\title{
Crystal and Microstructure Analysis of Pozzolanic Properties of Bamboo Leaf Ash and Locust Beans Pod Ash Blended Cement Concrete
}

\author{
*11IKUMAPAYI, CATHERINE MAYOWA
}

\author{
Civil and Environmental Engineering Department \\ Federal University of Technology, Akure, Nigeria \\ mayowaik@yahoo.com
}

\begin{abstract}
Pozzolans have been discovered recently to be of various benefits to the construction industries and various researches are on the high gear to further discover, proof and established their suitability as substitute to cement. This research work has therefore work on the effectiveness of bamboo leaf ash (BLA) and locust beans pod ash (LPBA) as pozzolans with reference to crystal and microstructure of its hydrated paste. Ordinary Portland cement was partially replaced with BLA and LPBA at different percentages, concrete pastes were made and cured at 7 and 28 days for the tests. The research work has been carried out using compressive strength test, X-ray fluorescence spectrometer, X-ray diffraction analysis as well as scanning electron microscopy to discover, present and analyze the quality and quantity of composition and hydration behavior of the different paste. The tests established BLA and LBPA as capable of successfully replacing cement in concrete production with added advantages in the properties of such concrete in term of mineral composition and microstructure interlocking. (c) JASEM
\end{abstract}

http://dx.doi.org/10.4314/jasem.v20i4.6

Keywords: Concrete, pozzolans, microstructure, crystal, hydration, silica @JASEM

Construction industry relies heavily on cement mostly ordinary Portland cement (OPC) for its operation in the production of concrete for development of shelter and other infrastructural facilities (Alabadan et al. , 2005; Adole et al., 2011). However, its production consumes a huge amount of energy combined with emission of harmful gases which pollutes the atmosphere (Energy and Climate, 2012). Partial replacement of OPC with pozzolans has been discovered to be of very good solution to these problems and their usage is highly encouraged (Arum et al., 2013). Past research outputs also revealed that they possess various benefits like increase compressive strength and improvement in the other durability properties of concrete if OPC is partially replaced by them (Rojas and Cabrera, 2002; Ikumapayi et al., 2015). Pozzolans such as rice husk ash have gained acceptance as supplementary cementing materials in many parts of the world (Adole et al., 2011). In recent times, many waste materials like fly ash, periwinkle shell ash, and ashes produced from various agricultural wastes such as palm oil waste, rice husk ash, corncob ash, millet husk ash, groundnut husk ash have been tried as pozzolans or secondary cementitious materials (Adole et al., 2011; Ikumapayi, 2014). Some new emerging biogenic pozzolans need to be established especially some waste agricultural products which has the ability to serve dual purposes. More details of the pozzolanic properties of these biogenic ashes will further established them and made them acceptable. $\mathrm{X}$-ray powder diffraction (XRD) is a rapid analytical technique primarily used for phase identification of a crystalline material and can provide information on unit cell dimensions

(serc.carleton.edu/research_education/geochemsheets /techniques/XRD.html). Also electron scanning microscope produces images of a sample by scanning it with a focused beam of electrons. The electron interacts with atom in the samples, producing various signals that contain information about the sample's surface topography and composition (www.nanoscience.com/technology/sem-

technology/). X-Ray Fluorescence Spectrometer is an effective non-destructive technique of analyzing the elemental and oxide crystal composition of a material (Beckhoff et al., 2006). Compressive strength is a measure of the concrete's ability to resist load which tends to crush it. Compressive and tensile strength tests are two major strength tests conducted on concrete. Strength normally gives an overall picture of the quality of a concrete because it is directly related to the structure of the cement paste. Compression test of the concrete specimen is most widely used test to measure its compressive strength (BS EN 206-1, 2006). Therefore these methods were simultaneously utilized in this research work to maximally bring out the features, microstructure and hydration behavior of these pozzolans. This research work has therefore work on the effectiveness of bamboo leaf ash (BLA) and locust beans pod ash (LPBA) as pozzolans with reference to crystal and microstructure of its hydrated paste.

\section{MATERIALS AND METHODS}

The materials used in this research work were Bamboo leaf ash (BLA), Locust beans pod ash 
(LPBA), sand (fine aggregate), granite (coarse aggregate), cement (OPC, Dangote type) and clean water for mixing as well as the curing medium.

Sample Collection: Bamboo leafs were collected as the fall off from the main bamboo trees and locust beans pod were collected after the yellow edible seed has been removed. The bamboo dried bamboo leafs and locust beans pods were dried and burnt to a temperature of $600^{\circ} \mathrm{C}$ and $500^{\circ} \mathrm{C}$ for 1 hour to form BLA and LPBA respectively.

Methods of Physical Analysis: Particle size distribution analysis (with minimum sieves size $50 \mu \mathrm{m}$ ) as well as the hygrometer test were carried out for the ashes obtained. Particle size analysis was also done for the sand while aggregate crushing value $(\mathrm{ACV})$ and aggregate impact value (AIV) tests were done for the granites.

Hydrometer test: Hydrometer test was carried out using, timing device, measuring bowls, thermometer,

Where;

$$
R=R^{1}+c t
$$

1 Equation 1

$\mathrm{R}=$ corrected hydrometer reading

$\mathrm{R}^{1}=$ original hydrometer reading

$\mathrm{Ct}=$ control hydrometer reading $(2$ in this case $)$

stationeries, weighing balance, stirrer, $0.075 \mathrm{~mm}$ sieve, drying oven and $1000 \mathrm{~mm}^{3}$ cylinders.

About $60 \mathrm{~g}$ of the sample was wet sieved using the $0.075 \mathrm{~mm}$ sieve and the filtrate was left to settle. Water was gently poured off while the sediment was placed in a drying oven for $24 \mathrm{hrs}$. $50 \mathrm{~g}$ of the ovendried sample was measured and placed in the cylinder. The cylinder was filled up with water up to the $1000 \mathrm{~mm}^{3}$ mark and stirred vigorously while preventing loss of the sample. The hydrometer bulb was placed in the cylinder and hydrometer readings were taken at different time intervals, the last reading taking place $24 \mathrm{hrs}$ after stirring the sample. Another cylinder was filled completely with water and used for taking temperature readings simultaneously along with the hydrometer readings. The control hydrometer reading was also derived by taking hydrometer reading from a cylinder filled with water containing dispersing agent up to $50 \mathrm{ml}$. The corrected hydrometer readings were gotten using

The value of the temperature constant $(\mathrm{K})$ was derived from a table using the values of the measured temperature and the specific gravity of the material. Alternatively, the value of ' $\mathrm{K}$ ' could be derived using Equation 2.

$$
K=\sqrt{\frac{30}{G_{s}-1}}
$$

Where;

$\eta=$ coefficient of viscosity, derived from tables as a function of the measured temperature, and

$\mathrm{G}_{\mathrm{s}}=$ specific gravity of the material

The effective depth (L) was gotten from tables with respect to the corrected hydrometer reading (R). The diameter of sphere (D) was then gotten using Equation 3

$$
D=K \sqrt{\frac{L}{T}}
$$

Where;

$\mathrm{K}=$ temperature constant

$\mathrm{L}=$ effective depth

$\mathrm{T}=$ time from initiation of readings

The $\%$ passing partial was gotten from Equation 4 as shown below

Where

$$
\% \text { passing partial }=\frac{R \times a}{W_{s}} \times 100
$$

$\mathrm{R}=$ Corrected hydrometer reading

$\mathrm{W}_{\mathrm{s}}=$ oven dried weight of sample used (60g in this case)

$\mathrm{a}=$ correction factor derived from tables with respect to specific gravity of the sample

The \% passing total was derived using Equation 5 
The particle size distribution curve was plotted.

Aggregate crushing value (ACV) test: To determine the ACV for the granites, the aggregate passing through $12.5 \mathrm{~mm}$ and retained on $10 \mathrm{~mm}$ International Standard (IS) sieve were oven dried at a temperature of $100-110^{\circ} \mathrm{C}$ for $3-4$ hours. The cylinder was filled in three layers, each layer tamped with 25 strokes of the tamping rod. The weight of the aggregate was measured and recorded as $\mathrm{A}$. The surface of the aggregate was then levelled and the plunger inserted. The apparatus was then placed in the compression testing machine and loaded at a uniform rate until the sample fails. The sample was then sieved through a $2.36 \mathrm{~mm}$ IS sieve and the fraction passing through the sieve was weighed as B. The ACV was calculated using Equation 6

$A C V=\frac{B}{A} X 100$

Aggregates impact test: Also the AIV test was done to determine the aggregate impact value of coarse aggregates according to IS: 2386 (Part IV) - 1963. The sample was oven dried for 4 hours at a temperature of $100-110^{\circ} \mathrm{C}$ and cooled. The cylinder was loaded with the aggregates in three layers and tamped with 25 strokes of the tamping rod at each filling. The net weight of the aggregates was determined as A. The cup of the impact testing machine was fixed firmly in position on the base of the machine and the whole of the test sample placed in it and compacted with 25 strokes of the tamping rod. The hammer was raised to $380 \mathrm{~mm}$ above the upper surface of the aggregates in the cup and allowed to fall freely onto the aggregates. The test sample was subjected to a total of 15 such blows, each being delivered at an interval of not less than one second. The sample was removed and sieved through a $2.36 \mathrm{~mm}$ sieve. The fraction passing through was weighed as B. The ratio of the weight of the fines formed to the total sample was expressed as a percentage as shown in Equation 7. The test was repeated thrice and the mean value was calculated.

$A I V=\frac{B}{A} X 100$

Methods of Chemical Analysis: Chemical tests were carried out on the BLA and LBPA to determine their pozzolanic properties. Chemical analyses were conducted with the aid of X-ray Diffraction machine, Minipal 4 Energy Dispensing X-Ray Fluorescence
Spectrometer (EDXRF) as well as scanning electron microscope. Moisture content and loss of ignition tests were also carried out on these materials.

X-ray Diffraction analysis: X-ray Diffraction machine was used for identifying the atomic and molecular structure of crystals in the various paste mixes. The various mix components were pulverized after curing for 7 days in water. The $\mathrm{X}$-rays were generated by a cathode ray tube, filtered to produce monochromatic radiation, collimated to concentrate, and directed toward the various samples. Diffraction occurs when light is scattered by a periodic array with long-range order, producing constructive interference at specific angles. The atoms in a crystal are arranged in a periodic array and thus can diffract light. The wavelengths of X-rays are similar to the distance between atoms. The scattering of X-rays from atoms produces a diffraction pattern, which contains information about the atomic arrangement within the crystal. The interaction of the incident rays with these samples produces constructive interference (and a diffracted ray) when conditions satisfy Bragg's Law $(\mathrm{n} \lambda=2 \mathrm{~d} \sin \theta)$. This law relates the wavelength of electromagnetic radiation to the diffraction angle and the lattice spacing in a crystalline sample. The characteristic $\mathrm{x}$-ray diffraction pattern generated in these XRD analyses provides unique information of the crystals present in these samples. They were properly interpreted, by comparing with standard reference patterns and measurements which help in the identification of the crystalline form.

$X$-ray fluorescence analysis: MiniPal 4 Energydispersive X-ray fluorescence (XRF) bench-top spectrometer was also used to perform nondestructive chemical analysis of elemental oxides present in the different pozzolans used. The BLA and LBPA were loaded into the sample holder and placed in the appropriate sample tray. The test was carried out by bombarding the samples with high energy Xrays which resulted into emission of characteristics secondary X-rays. Through the use of silicon drift detector the elemental analysis and oxide composition were determined and printed out through the attached computer and printer.

Scanning Electron Microscopic Analysis: In carrying out SEM analysis, the paste samples (of about $20 \mathrm{~mm}$ diameter) were prepared to fit in into the specimen chamber and they were mounted rigidly on the 
specimen stub. Their surfaces were polished to an ultra-smooth surface and were coated with carbon. Secondary electron detectors were used and the data were displaced by a computer device.

Loss on ignition test: Loss on ignition test was done by heating up BLA and LBPA to a temperature between $900^{\circ} \mathrm{C}$ to $1000^{\circ} \mathrm{C}$ until a constant weight was obtained. The weight of the various samples due to heating was then determined and recorded.

Test and Analysis of Concrete Specimens: Concrete specimens of size $150 \mathrm{~mm}$ x $150 \mathrm{~mm}$ x $150 \mathrm{~mm}$ were produced by partially replacing OPC with BLA and LPBA at $0 \%, 8 \% 12 \%$ and $16 \%$. They were cured for 7 and 28 days in water and later brought out to be used for the compressive strength test in accordance with BS EN 206-1 (2006). A concrete mix of ratio 1:2:4 (cement: sand: aggregates) were adopted for the production of all the concrete cubes at water/cement ratio $(\mathrm{c} / \mathrm{w})$ of 0.6 . Also various cement paste with mix ratio 1:6 (cement: sand) of $50 \mathrm{~mm}$ x $50 \mathrm{~mm}$ x 50 mm dimension were made with the cement partially replaced with BLA at $0 \%, 8 \%$ and $16 \%$. The pastes were cured for 7 and 28 days duration and then analysed using X-ray diffraction analysis and scanning electron microscopy (SEM) studies.

Analyses of variance (ANOVA) and least significant different (LSD) tests: The results of the compressive strength test were compared using analyses of variance (ANOVA) and least significant different (LSD) tests as post hoc test. ANOVA is the table that shows the output of the ANOVA analysis and whether we have a statistically significant difference between our group means while LSD post hoc test shows which groups differed from each other.

\section{RESULTS AND DISCUSSION}

The results of the particle size distribution and the hygrometer tests for BLA and LBPA are shown in Figures 1 and 2 . These results showed BLA to have greater percentage of micro particles $(<50 \mu)$ than LBPA which contributes to its better performance than LBPA in term of compressive strength as shown in Figures 4 and 5. Particle size distribution chart for the sand is also shown in Figure 3. The results of the ACV and AIV for the granites chippings were $29.8 \%$ and $18.2 \% \quad$ respectively.

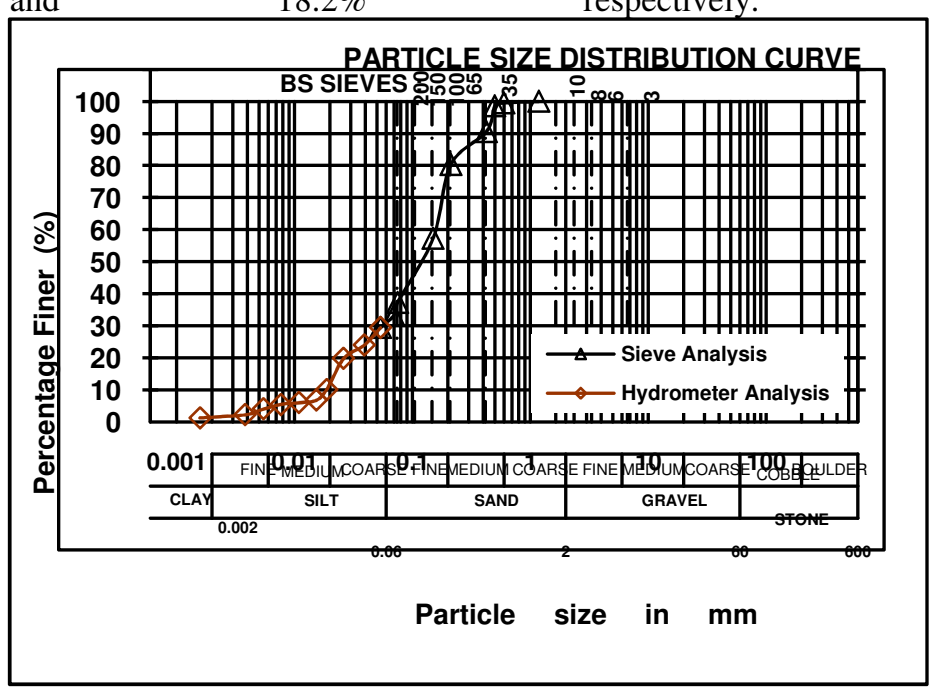

Fig 1: Particle size distribution curve for BLA

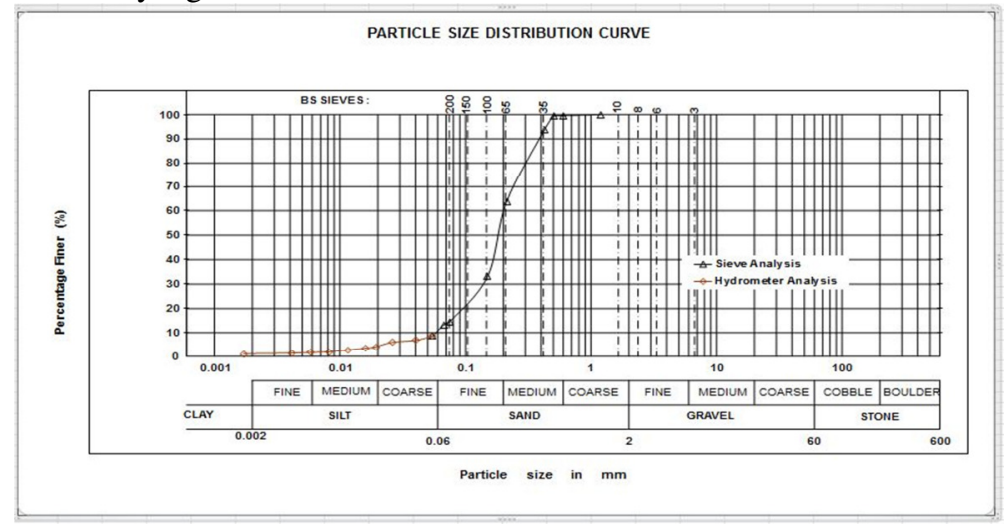

Fig 2: Particle size distribution curve for LBPA 


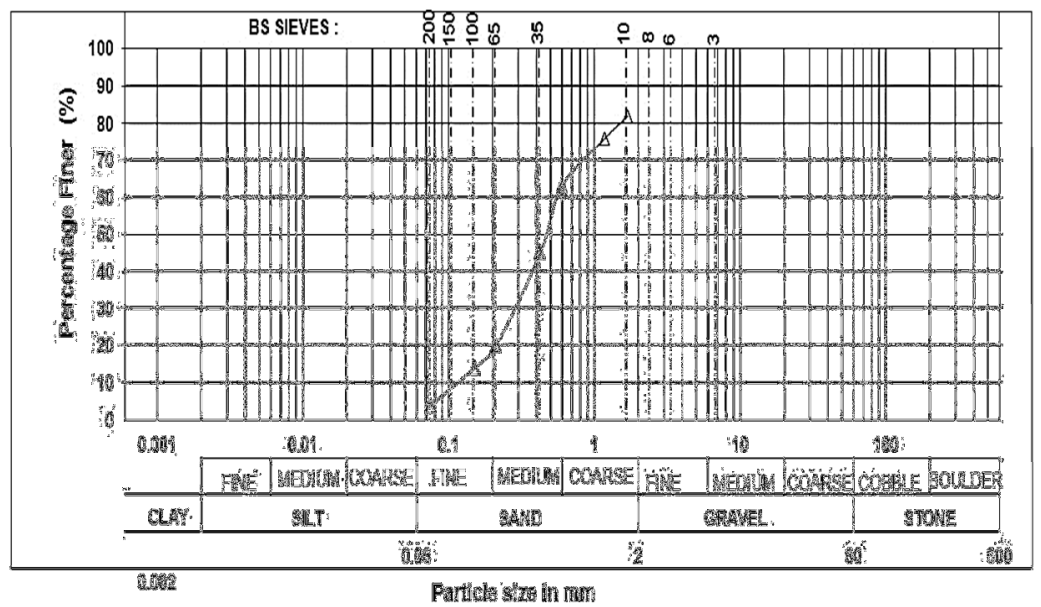

Fig 3: Particle size distribution curve for the sand

The result of the chemical analyses conducted using EDXRF is presented in Table 1 . The result was compared with the standard specified by ASTM 618 (1999) and presented in Table 2. The results of the chemical composition for these pozzolans show that they belong to the group of pozzolanic material; they satisfy most of the requirement specified by ASTM C618 (1999). BLA satisfied three of the requirements; it has $85.5 \%$ of $\mathrm{SiO}_{2}+\mathrm{Al}_{2} \mathrm{O}_{3}+\mathrm{Fe}_{2} \mathrm{O}_{3}$, no SO3, and $5.0 \%$ loss on ignition but $9.1 \%$ moisture content which is higher than the maximum of $3.0 \%$ in the specification. LBPA did not satisfy the first required in Table 2, addition of Silicon dioxide $\left(\mathrm{SiO}_{2}\right)$ plus Aluminium oxide $\left(\mathrm{Al}_{2} \mathrm{O}_{3}\right)$ plus iron oxide $\left(\mathrm{Fe}_{2} \mathrm{O}_{3}\right)$ is $25.2 \%$ which is less than $50 \%$ minimum requirement; but it satisfies the other requirements, Sulphur trioxide $\left(\mathrm{SO}_{3}\right)$ present is $3.6 \%$ which is less than the maximum of 4.0 and 5.0 for any of the classes, the moisture content of 3.0 and loss on ignition of 2.0 are all within the specified range

Table 1: Chemical composition of the major required oxides of pozzolans

\begin{tabular}{|c|c|c|c|c|}
\hline Constituent & $\begin{array}{l}\text { \% Composition } \\
\text { (BLA) }\end{array}$ & $\begin{array}{l}\% \\
\text { (LBPA) }\end{array}$ & Composition & $\begin{array}{l}\text { \% Composition } \\
\text { OPC }\end{array}$ \\
\hline Ferrous oxide $\left(\mathrm{Fe}_{2} \mathrm{O}_{3}\right)$ & 11.5 & 7.19 & & 4.65 \\
\hline Silica $\left(\mathrm{SiO}_{2}\right)$ & 53 & 18 & & 22.00 \\
\hline Calcium Oxide $(\mathrm{CaO})$ & 3.4 & - & & 62 \\
\hline Aluminum Oxide $\left(\mathrm{Al}_{2} \mathrm{O}_{3}\right)$ & 21 & - & & 5.03 \\
\hline Magnesium Oxide (MgO) & 0.88 & 0.48 & & 2.06 \\
\hline Sodium Oxide $\left(\mathrm{Na}_{2} \mathrm{O}\right)$ & - & - & & 0.19 \\
\hline Potassium Oxide $\left(\mathrm{K}_{2} \mathrm{O}\right)$ & 1.3 & 61.8 & & 0.40 \\
\hline Sulphite $\left(\mathrm{SO}_{3}{ }^{2-}\right)$ & - & 3.6 & & 1.43 \\
\hline Loss on ignition (LOI) & 2.0 & 4.0 & & \\
\hline
\end{tabular}

Table 2: Comparison of the chemical requirements and the pozzolanic composition

\begin{tabular}{llllll}
\hline Chemical Requirement & \multicolumn{2}{l}{ Class } & & \\
\cline { 2 - 6 } & $\mathrm{N}$ & $\mathrm{F}$ & $\mathrm{C}$ & $\mathrm{BLA}$ & $\mathrm{LBPA}$ \\
$\mathrm{SiO}_{2}+\mathrm{Al}_{2} \mathrm{O}_{3}+\mathrm{Fe}_{2} \mathrm{O}_{3}$, min. \% & 70.0 & 70.0 & 50.0 & 85.5 & 25.2 \\
$\mathrm{SO}_{3}$, max. \% & 4.0 & 5.0 & 5.0 & - & 3.6 \\
Moisture content, max. \% & 3.0 & 3.0 & 3.0 & 9.1 & 3.0 \\
Loss on ignition, max., \% & 10.0 & $6.0^{\mathrm{A}}$ & 6.0 & 2.0 & 2.0 \\
\hline
\end{tabular}

${ }^{A}$ The use of Class $\mathrm{F}$ pozzolan containing up to $12.0 \%$ loss on ignition may be approved subject to acceptable performance records or laboratory test results.

Silicon dioxide $=\mathrm{SiO}_{2}$, Aluminium oxide $=\mathrm{Al}_{2} \mathrm{O}_{3}$, Iron oxide $=\mathrm{Fe}_{2} \mathrm{O}_{3}$, Sulphur trioxide $=\mathrm{SO}_{3}$ Effect of partial replacement of OPC with BLA and LPBA on compressive strength was investigated using at $0 \%, 8 \%, 12 \%$ and $16 \%$ percentage replacement. The results of the compressive strength obtained for 7 days and 28 days are shown in Figures 4 and 5 respectively. It can be observed from the result that the compressive strength increases with increase in the percentage replacement of BLA and LPBA at both 7 and 28 days curing. The point of maximum compressive strength lies at $8 \%$ OPC replacement for both pozzolans while the same value 
of strength was obtained for OPC and the pozzolans at $12 \%$. At $16 \%$ replacement, there is a drastic reduction in the compressive strength of the concrete. These results show that some strength forming reactions takes place when these pozzolans were partially used to replace cement from $0 \%$ to $8 \%$, after which the reactions reduces and the compressive strength dropped. The various phases of the percentage replacement were studied using X- Ray diffraction analysis and SEM studies.

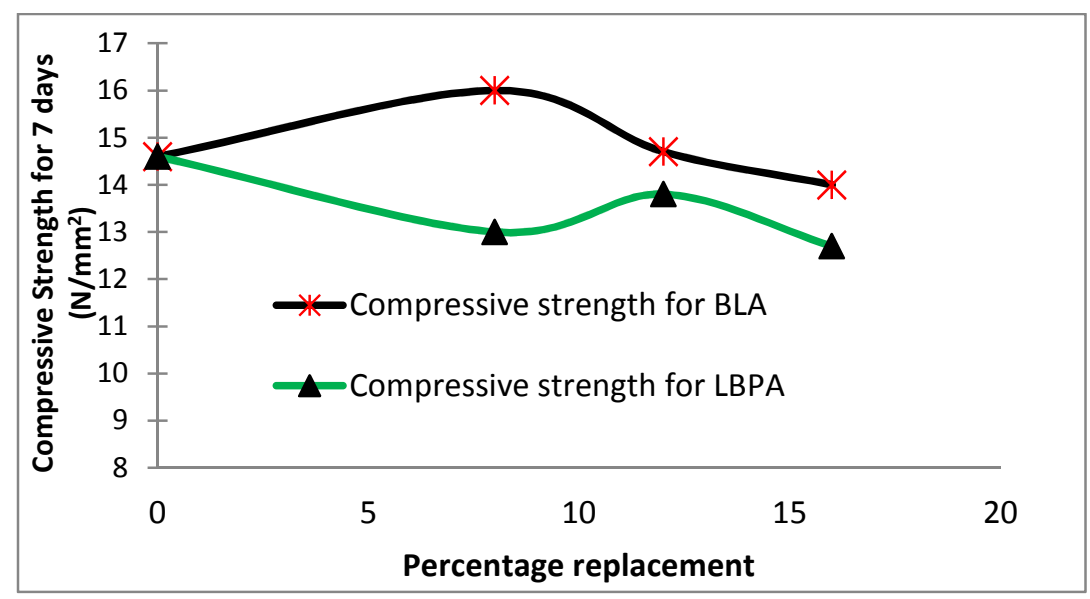

Fig 4: Trends of the compressive strength of BLA and LPBA pozzolanic concrete at 7 days curing

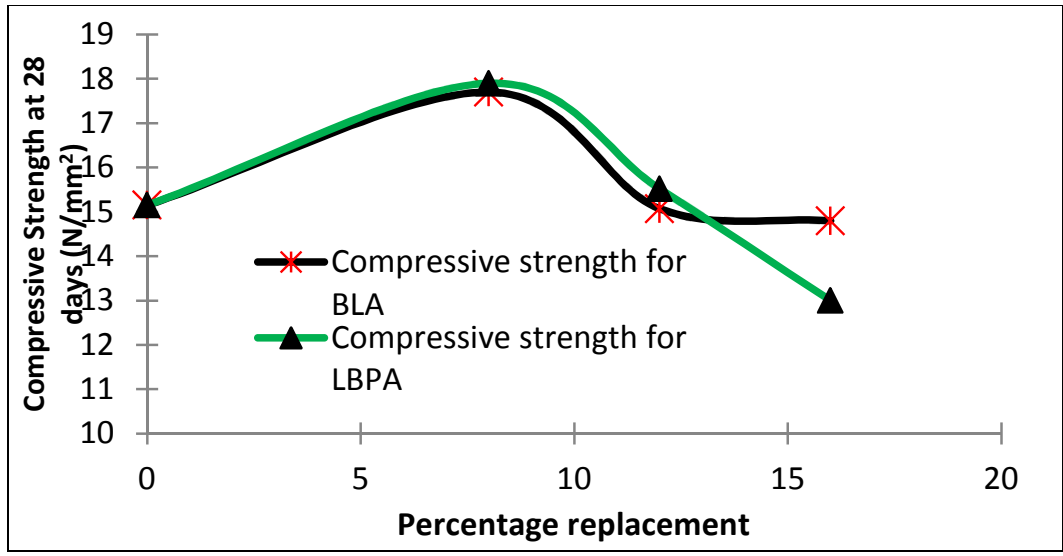

Fig 5: Trends of the compressive strength of BLA and LPBA pozzolanic concrete at 28 days curing

The results of the 28 days compressive strength test were compared using ANOVA and LSD tests and the outputs are shown in Tables 3 and 4 . The tests show that there were significant differences in the compressive strength obtained for OPC when compared with BLA $8 \%$, LPBA $8 \%$ and LBPA $16 \%$. BLA8\% and LPBA8\% showed a significant strength increment while LBPA (16\%) showed a significant strength reduction. These results in conjunction with results in Figure 5 further showed that BLA12\% and LBPA12\% can replace OPC in concrete production without altering the compressive strength significantly while the reduction in the compressive strength by BLA16\% is not also significant 
Table 3: LSD test for 28 days compressive strength, 1-OPC (control),

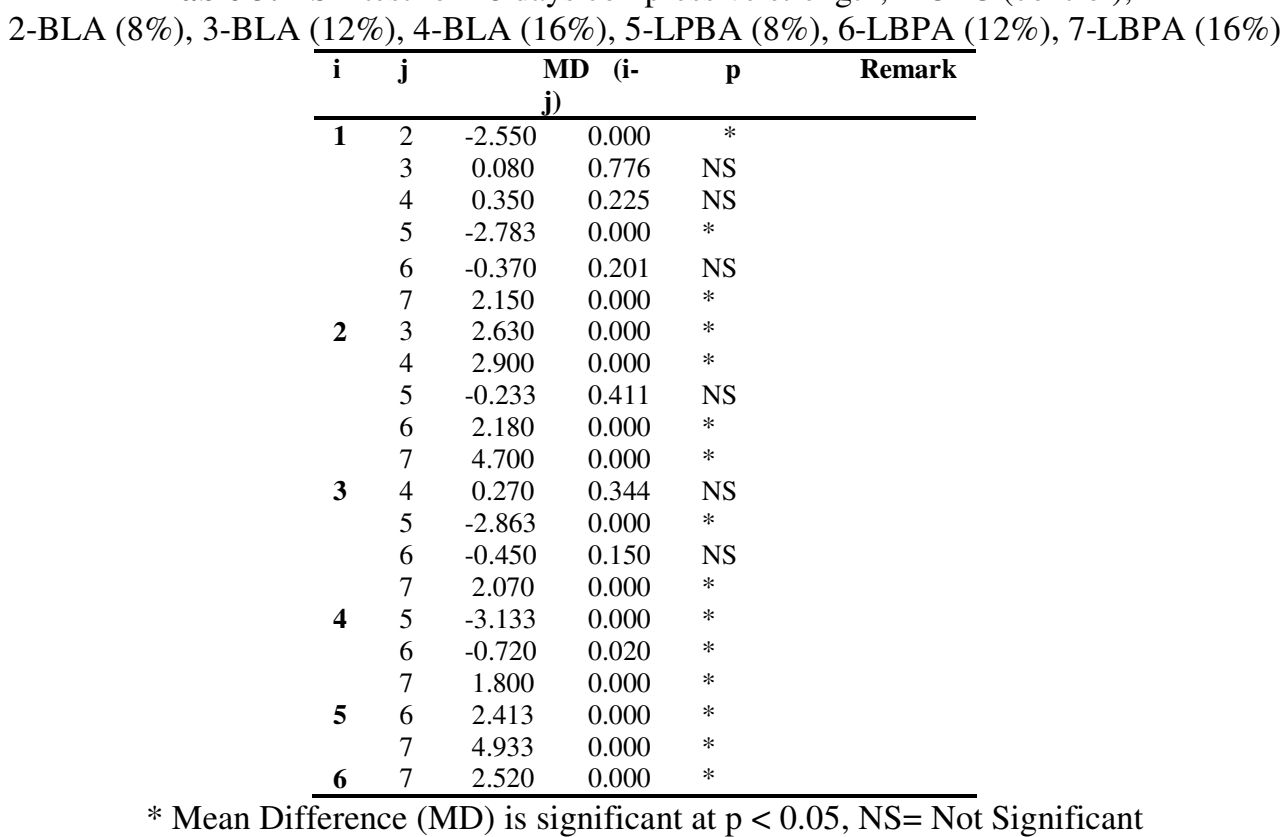

Table 4: One way ANOVA Result for 28 days compressive strength for BLA and LBPA

\begin{tabular}{llllcl}
\hline & Sum of Squares & df & Mean Square & F & Sig. \\
Between Groups & 53.232 & 6 & 8.872 & 77.939 & 0.000 \\
Within Groups & 1.594 & 14 & 0.114 & & \\
Total & 54.826 & 20 & & & \\
\hline
\end{tabular}

The X-ray diffraction pattern obtained for OPC, BLA $8 \%$ and BLA25\% pastes at 7 day are shown in Figures 6 to 8 . The results show the composition of the various minerals and compounds present in each of the paste with their intensities. The X-ray diffraction patterns were determined for OPC, BLA $8 \%$ and BLA25\% pastes at 7 day in order to explain the mechanism behind their hydration behavior. The results of the XRD pattern as well as XRF show the prevalent of silica in BLA paste and ash respectively. The result in Figure 7 for BLA8\% paste shows the presence of more and higher peak of silica when compared with the result in Figure 6 for OPC paste. This an indication of more covalent bond and therefore more stability in BLA $8 \%$ paste than OPC paste. While in BLA $25 \%$ paste there is also a considerable amount of silica which can be compared to that of BLA $8 \%$ but the effective percentage required has been exceeded as shown in the compressive strength result. The presence of silica symbolizes stability; The more silica, the more covalent bonding and the greater the stability to chemical weathering. Silica $\left(\mathrm{SiO}_{4}\right)$ possesses tetrahedron structure and is covalently bonded to four oxygen atoms at the corner of a triangular pyramid shape. The bonding that takes place during the cement hydration depends on the availability of either more silica or cations like $\mathrm{K}^{+}, \mathrm{Na}^{+}, \mathrm{Ca}^{2+}, \mathrm{Mg}^{2+}, \mathrm{Fe}^{2+}$, etc. In the presence of more silica, each tetrahedron will be bonded together covalently by sharing oxygen atoms between adjacent tetrahedral. In this way they may form single chains, double chains, sheets, and 3dimensional networks of interlocking tetrahedral which are consider being more stable. On the other hand, each tetrahedral may be isolated from one another and each of these covalently bonded structural groups (except framework) is bonded to its neighboring structural group (e.g. single chain to single chain) by ionic bonds with the intervening cations. Unlike covalent bond, the more cations and ionic bonding, the lower the weathering stability. Covalent bond required greater energy before it can be broken (Berg et al., 2002).

Furthermore Figures 6 to 8 show peaks of the unreacted calcite $\left(\mathrm{CaCO}_{3}\right)$ and the calcium silicate hydrate $(\mathrm{C}-\mathrm{S}-\mathrm{H})$ phase formed after the 7 days hydration reaction. The peak and integrated intensity of the available $\mathrm{CaCO}_{3}$ after hydration of the OPC, BLA $8 \%$ and BLA25\% pastes shows that OPC has a higher content of $\mathrm{CaCO}_{3}$ than $\mathrm{BLA} 8 \%$ while BLA25\% has the highest $\mathrm{CaCO}_{3} . \mathrm{CaCO}_{3}$ is one of the raw materials for the production of cement (Mindess et al., 2003) ; its lesser content and peak in 
BLA8\% shows better hydration in BLA8\% when compared with OPC and BLA25\%. Also the increase in the amount of $\mathrm{CaCO}_{3}$ obtained in $\mathrm{BLA} 25 \%$ is an indication that the optimum amount of BLA

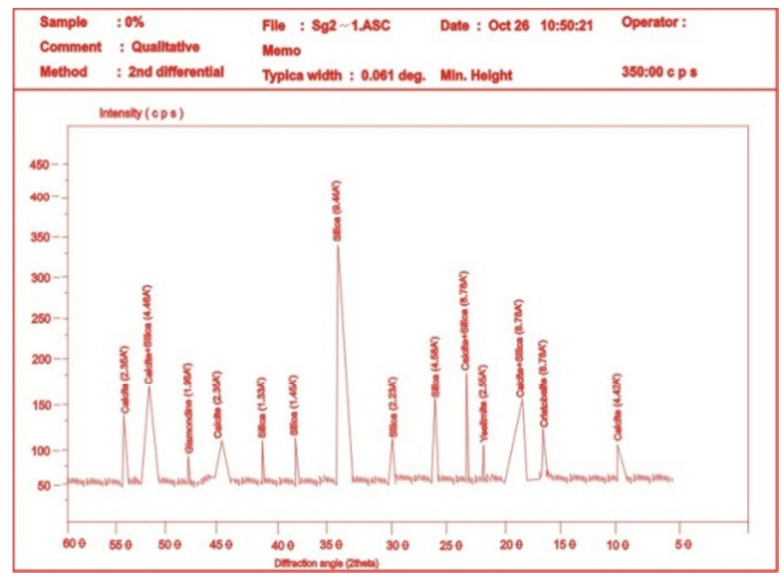

Fig 6: X-ray Diffraction pattern for 0\% of BLA at 7 days curing percentage replacement needed for effective pozzolanic reaction has been exceeded which subsequently reduces its pozzolanic effectiveness.

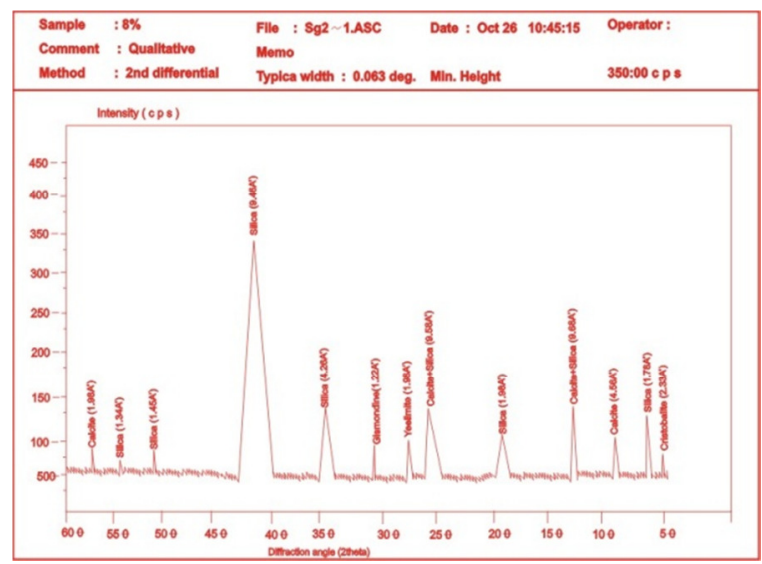

Fig 7: X-ray Diffraction pattern for $8 \%$ of BLA at 7 days curing

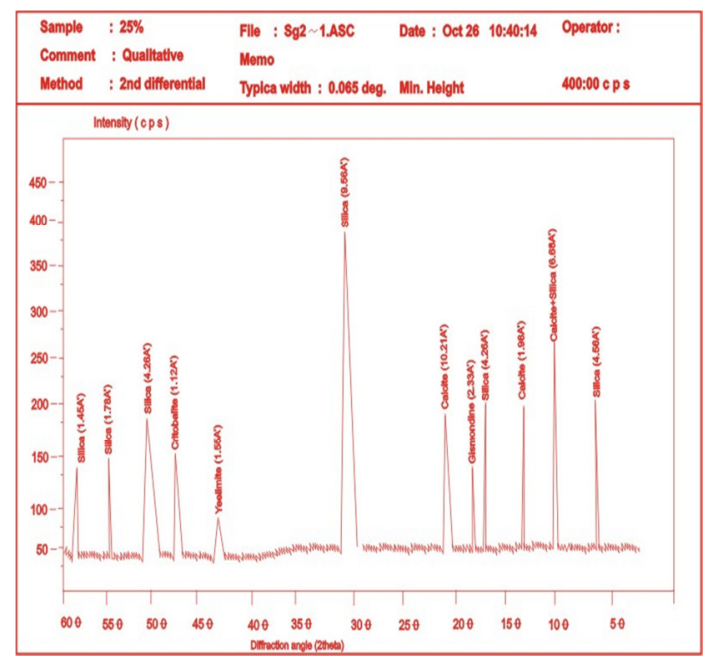

Fig 8: X-ray Diffraction pattern for $25 \%$ of BLA at 7 days curing

The result of the SEM pictures for hydrated samples of OPC, BLA $8 \%$ and BLA16\% at 28 days curing are shown in Figures 8 to 10.The result shows that the image of BLA8\% is tightly interlocked when compared with OPC and BLA16\%, while that of OPC gives a better mechanical interlocked than
BLA16\%. This result further supports that addition of pozzolanic material to concrete will improve the micro structural property of such concrete which in turn will improve the other properties like compressive strength ( Figures 3 and 4 ) and durability 


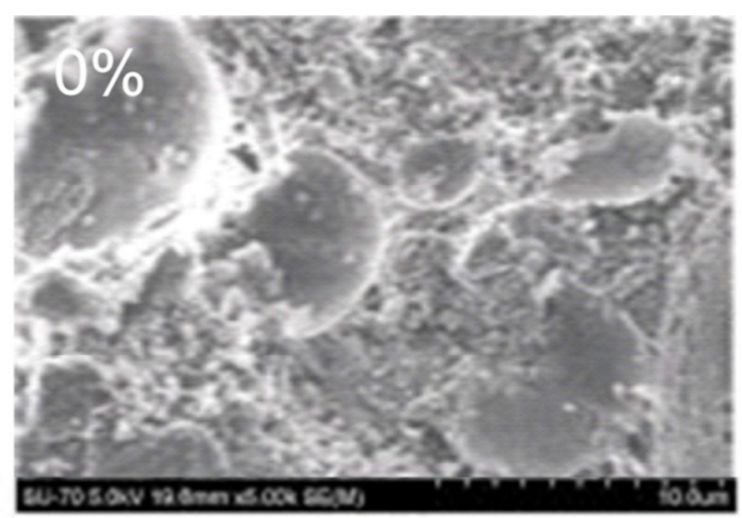

Fig 9: SEM pictures for OPC paste hydrated at 28 day

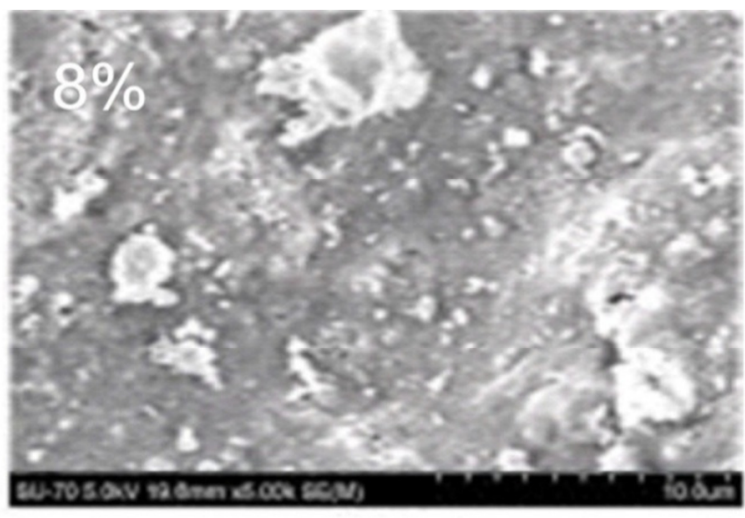

Fig 10: SEM pictures for BLA8\% paste hydrated at 28 day

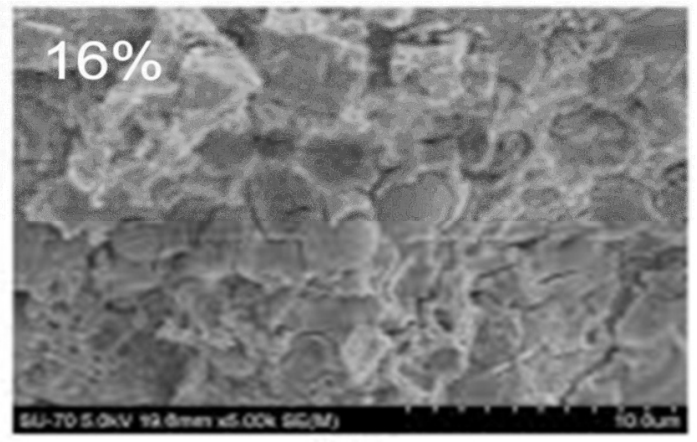

Fig 11: SEM pictures for BLA16\% paste hydrated at 28 day

Based on the outcome of this research, it can be concluded that both BLA and LBPA are pozzolans which when partially replaced with OPC will affect the hydration products as well as the mechanical interlock or microstructure of such concrete. Crystalline silica is one of the main chief elements that contribute to pozzolanicity in pozzolans. The optimum percentage replacement of BLA and LBPA lies between $8 \%$ and $16 \%$. The optimum percentage replacement of both BLA and LBPA should be adhered to for effective performance.

\section{REFERENCES}

Adole, MA; Dzasu, WE; Umar, A; Oraegbune, OM (2011). Effects of Groundnut Husk Ash-blended Cement on Chemical Resistance of Concrete. ATBU Journal of Environmental Technology 4 (1): 23-32.

Alabadan, B A; Olutoye, MA; Abolarin,M.S; Zankariya, M (2005). Partial replacement of Ordinary Portland Cement (OPC) with Bambara Groundnut Shell Ash (BGSA) in Concrete. Leonardo Electronic Journal of Practices and Technologies 6: 43- 48.

Arum, C; Ikumapayi CM; Aralepo GO (2013). Ashes of Biogenic Wastes-Pozzolanicity, Prospects for Use, and Effects on Some Engineering Properties of Concrete. Materials Sciences and Applications 4: 521-527.

ASTM C618 - 12a (1999).

Standard Specification for Coal Fly Ash and Raw or Calcined Natural Pozzolan for Use in Concrete. ASTM International, West Conshohocken, PA, USA, p5.

Beckhoff, B; Kanngieber, B; Langhoff, N; Wedell, R; Wolff, H (2006) Handbook on practical X-Ray Fluorescence Analysis (Eds). Springer Berlin Heidelberg, Newyork, 845.

Berg, JM; Tymoczko JL; Stryer L (2002). Biochemistry. $5^{\text {th }}$ Edition. New York, W.H Freeman. Available from: http://www.ncbi.nlm.nih.gov/books/NBK21154/

BS EN 206-1. (2006). Concrete Complementary British Standard to BS EN 206-1, part 1-Method of Specifying and Guidance for Specifier, European Standard published by BSI, p66.

Energy and Climate, chapter 5 from the book Entrepreneurship and Sustainability (1.0).

Creative Commons. Retrieved from 
http://2012books.lardbucket.org/books/entrepren eurship-and-sustainability/index.html assessed on $28^{\text {th }}$ March, 2015.

Ikumapayi, CM (2014). Properties of Groundnut Shell Ash Blended Portland cement. Civil Engineering: the Cradle of National Economic Growth held in Lagos, organised by the Nigeria Institute of Civil Engineers, 58-67.

Ikumapayi, CM; Arum C; Oguntunde PG (2015). Making Durable Concrete through Inhibition of Chloride Ion penetration by Pozzolanic Action" Proceedings of the $1^{\text {st }}$ symposium of Knowlegde Exchange for Young Scientists (KEYS): SubSaharan African Standards for Cement and Concrete Research \& Raw materials, Quality Control and Maintenance of Cementitious products held in Dar es Salaam Tanzania, 9 -11th June, 2015: 145-149
IS: 2386 -Part IV (1963). Methods of test for aggregates for concrete, part iv, mechanical properties by bureau of Indian Standard, p484.

Mindess, S; Young, JF; Darwin, D (2003). Concrete, Second edition, Prentice Hall, New Jersey, USA, p644.

Rojas MF. and Cabrera J. (2002). The effect of Temperature on the Hydration rate and Stability of the Hydration Phases of metakaolin-lime water systems, Cement and Concrete Research 32: $133-138$

serc.carleton.edu/research_education/geochemsheets/ techniques/XRD.html assessed on $9^{\text {th }}$ May. 2016 www.nanoscience.com/technology/semtechnology/ assessed on $9^{\text {th }}$ May, 2016. 